\title{
Incidence and Mortality of Breast Cancer and their Relationship to Development in Asia
}

\author{
Mahshid Ghoncheh ${ }^{1}$,Abdollah Mohammadian-Hafshejani ${ }^{2}$,Hamid Salehiniya $a^{3,4 *}$
}

\begin{abstract}
Purpose: This study aimed to investigate the incidence and mortality of breast cancer, and its relationship with human development index (HDI) and its components in Asia in 2012. Materials and Methods: This study was an ecologic study in Asia for assessment of the correlation between age-specific incidence rate (ASIR) and age-specific mortality rate (ASMR) with HDI and its details that include: life expectancy at birth, mean years of schooling and gross national income (GNI) per capita. Data about SIR and SMR for every Asian country for the year 2012 were obtained from the global cancer project. We used a bivariate method for assessment of the correlation between SIR and SMR and HDI and its individual components. Statistical significance was assumed if $\mathbf{P}<0.05$. All reported $P$-values are two-sided. Statistical analyses were performed using SPSS (Version 15.0, SPSS Inc.). Results: In 2012, 639,824 cases of breast cancer were recorded in Asian countries. Countries with the highest standardized incidence rate (ASIR) (per 100,000) were Israel (80.5), Lebanon (78.7), Armenia (74.1) and the highest standard mortality rate (ASMR) was observed in Pakistan (25.2), Armenia (24.2), and Lebanon (24). There was a positive correlation between the ASIR of breast cancer and HDI $(r=0.556, p<0.001)$, whereas there was a negative correlation between the ASMR of breast cancer and HDI $(r=-\mathbf{- 0 . 0 5 1})$. Conclusions: Breast cancer incidence in countries with higher development is greater, while mortality is greatest in countries with less development. There was a positive and significant relationship between the ASIR of breast cancer and HDI and its components. Also there was a negative but non significant relationship between the ASMR of breast cancer and HDI.
\end{abstract}

Keywords: Breast cancer - human development index - incidence - mortality - Asia

Asian Pac J Cancer Prev, 16 (14), 6081-6087

\section{Introduction}

Cancer is one of the most important health problems in the world. In developed countries, $55 \%$ of the burden of diseases is associated with cancer (Ferlay et al., 2010a). The incidence of cancer is rapidly increasing in the developing world (Youlden et al., 2014). Breast cancer is the most common cancer in women. More than 1.3 million patients suffering from the cancer are diagnosed each year in the world (Grayson, 2012). More than 508,000 women in the world have lost their lives due to breast cancer in 2011. The incidence of breast cancer varies from 89.7 per 100,000 in East Africa to 19.4 per 100,000 people in West Europe (WHO, 2015a). Breast cancer is the most common malignancies in Asian women (Grayson, 2012). This is increasing in Asian countries with a sharp slope (Keyghobadi et al., 2015). Although the incidence rate is lower in Asian countries than in Europe and the United States, the death rate from breast cancer is considerable in Asia (Jemal et al., 2011). A history of cancer registration is very different in
Asian countries (Shin et al., 2012). Most Asian countries emit reports on the incidence rate of the cancer, which are arguable their coverage and accuracy (Ferlay et al., 2010b). Studies showed that preventive programs are better if they will be applied in any region for the most common cancers. Population-based cancer registration is suggested for control of cancer (Roshandel et al., 2014). Studies also revealed that early detection of the cancer is important in reducing the mortality rate and improving prognosis (Rahimzadeh et al., 2014). The survival rate is different in the world, in the North of United States more than $80 \%$ and in low income countries less than $40 \%$. The low survival in not developed countries is more related to lack of diagnostic and screening programs and treatment facilities (WHO, 2015a).The residence area and socio-economic status are also associated with the stage of cancer diagnosis (Abbastabar et al., 2013). According to studies performed, low percentage of population has well know awareness of effective factors in developing cancer and diagnostic procedures (Ray and Mandal, 2004). Low educated mothers seek lower treatment

${ }^{1}$ Department of Epidemiology and Biostatistics, School of Public Health, Hamadan University of Medical Sciences, Hamadan, ${ }^{2}$ Department of Epidemiology and Biostatistics, School of Public Health, Isfahan University of Medical Sciences, Isfahan, ${ }^{3}$ Minimally Invasive Surgery Research Center, Iran University of Medical Sciences, ${ }^{4}$ Department of Epidemiology and Biostatistics, School of Public Health, Tehran University of Medical Sciences, Tehran, Iran*For correspondence: alesaleh70@yahoo.com 
facilities (Ramadas et al., 2015). A direct relationship was observed between women's information and acquiring their healthy behaviors, such as breast examination (Chen et al., 2014). Low information in women, low budget, and lack of insurance and screening programs are problems in implementation of cancer prevention and treatment programs n Asia (Agarwal et al., 2007). In some Asian countries, like Hong Kong, South Korea, Taiwan, and Thailand, effective screening programs are implemented (Sankaranarayanan et al., 2014).

To investigate conditions of countries, indicators have been defined. One of the most important indicators is the Human Development Index (HID), which assesses the condition or status of a country based on three fundamental aspects. The indicator is combination of lifetime, knowledge, and the standards of living. Lifetime is measured by life expectancy at birth, knowledge by years of potential education, and adequate standard of living by GDP per capita or income. HDI is a number between zero and one. According to HDI, countries in the world are divided into four categories: Countries with very high HDI (HDI $\geq 0.9$ ), countries with a high HDI (HDI $\geq 0.8$ ), Medium HDI countries (0.8> HDI $>0.5)$, and countries with a low HDI (HDI $\leq 0.5)$. The index was proposed by UNDP in 1990 as an indicator of comparison of countries in three human aspects. HDI was announced in 2013 on average in Arabic countries 0.682, East Asia and Pacific 0.703 , and South Asia 0.588 . The average of the indicator in some Asian countries is lower than the global average (0.702) (UNDP, 2014)

Chronic diseases such as breast cancer have many causes. A number of studies have mentioned the role of HDI associated with the incidence and mortality of breast cancer (Gonzaga et al., 2015). Information on the incidence and mortality of breast cancer can be useful for planning health and research activities. According to the possible impact of HDI, this study aimed to investigate the incidence and mortality of breast cancer, and its relationship with HDI and its components in Asia in 2012.

\section{Materials and Methods}

This study was an ecologic study in Asia for assessment the correlation between age-specific incidence rate (ASIR) and age-specific mortality rate (ASMR) with Human Development Index (HDI) and its details that include: Life expectancy at birth, Mean years of schooling and gross national income (GNI) per capita. Data about the age-specific incidence and mortality rate (ASIR) for every Asian counter for year 2012 get from global cancer project that available in (http://globocan.iarc.fr/Default. aspx) (Ferlay, 2013)and Human Development Index (HDI) from Human Development Report 2013 that include information about HDI and its details for every country in the word for year 2012 (Malik, 2013).

Method of estimate the age-specific Incidence and mortality rates in global cancer project by international agency for research on cancer

Age-specific incidence rate (ASIR)

The methods of estimation are country specific and the quality of the estimation depends upon the quality and on the amount of the information available for each country. In theory, there are as many methods as countries, and because of the variety and the complexity of these methods, an overall quality score for the incidence and mortality estimates combined is almost impossible to establish. However an alphanumeric scoring system which independently describes the availability of incidence and mortality data has been established at the country level. The combined score is presented together with the estimates for each country with an aim of providing a broad indication of the robustness of the estimation.

The methods to estimate the sex- and age-specific incidence rates of cancer for a specific country fall into one of the following broad categories, in priority order:

1- Rates projected to 2012 (38 countries)-2- Most recent rates applied to 2012 population (20 countries)3-Estimated from national mortality by modelling, using incidence mortality ratios derived from recorded data in country-specific cancer registries (13 countries)-4Estimated from national mortality estimates by modelling, using incidence mortality ratios derived from recorded data in local cancer registries in neighboring countries (9 European countries)-5-Estimated from national mortality estimates using modelled survival (32 countries)-6Estimated as the weighted average of the local rates (16 countries)-7- One cancer registry covering part of a country is used as representative of the country profile (11 countries)-8-Age/sex specific rates for "all cancers" were partitioned using data on relative frequency of different cancers (by age and sex) (12 countries)-9- The rates are those of neighboring countries or registries in the same area (33 countries) (Ferlay, 2013)

\section{Age-specific mortality rate (ASMR)}

Depending of the degree of detail and accuracy of the national mortality data, six methods have been utilized in the following order of priority: 1-Rates projected to 2012 (69 countries)-2- Most recent rates applied to 2012 population (26 countries)-3- Estimated as the weighted average of regional rates (1 country)-4- Estimated from national incidence estimates by modelling, using country-specific survival (2 countries)-5-Estimated from national incidence estimates using modelled survival ( 83 countries)-6-The rates are those of neighboring countries or registries in the same area (3 countries)

\section{Human development index (HDI)}

Human Development Index (HDI), a composite measure of indicators along three dimensions: life expectancy, educational attainment and command over the resources needed for a decent living. All groups and regions have seen notable improvement in all HDI components, with faster progress in low and medium HDI countries. On this basis, the world is becoming less unequal. Nevertheless, national averages hide large variations in human experience. Wide disparities remain within countries of both the North and the South, and income inequality within and between many countries has been rising (Malik, 2013).

Statistical analysis: In this study, we use of correlation 
bivariate method for assessment the correlation between ASIR and ASMR with HDI and its details that include Life expectancy at birth, Mean years of schooling and Gross national income (GNI) per capita. Statistical significance was assumed if $\mathrm{P}<0.05$. All reported $\mathrm{P}$-values are twosided. Statistical analyses were performed using SPSS (Version 15.0, SPSS Inc.).

\section{Results}

In 2012,639,824 cases of breast cancer were recorded in Asian countries. Five Asian countries with the highest number of cases were China (187,213 cases), India (144,937 cases), Japan (55,710 cases), Indonesia (48,998 cases, and Pakistan (34,038 cases), respectively. The five countries included 470,896 cases $(59 / 73 \%)$ of the cases in Asia.

In Asian countries, 5 countries with the highest standardized incidence rate of breast cancer (per 100,000) were Israel (80.5), Lebanon (78.7), Armenia (74.1), Singapore (65.7), and Kazakhstan (73.5), respectively. Five countries that had the lowest standardized incidence rate of breast cancer (per 100,000) included Butane (4.6), Mongolia (9.4), Nepal (13.7), Lao PDR (19), and Cambodia (19.3), respectively (Table1, Fgure1, Map1).

In 2012, 228,926 deaths occurred due to breast cancer in Asia. The highest number of deaths was observed in India, (70,218 cases), China (47,984 cases), Indonesia

Table 1. Incidence and Mortality of breast Cancer in Asia by Country

\begin{tabular}{|c|c|c|c|c|c|c|c|}
\hline Country & Numbers & Crude Rate & ASIR & country & Numbers & Crude Rate & ASMR \\
\hline Israel & 4010 & 103.0 & 80.5 & Pakistan & 16232 & 18.3 & 25.2 \\
\hline Lebanon & 1934 & 88.0 & 78.7 & Armenia & 609 & 36.7 & 24.2 \\
\hline Armenia & 1704 & 102.5 & 74.1 & Lebanon & 599 & 27.3 & 24.0 \\
\hline Singapore & 2524 & 96.8 & 65.7 & Jordan & 426 & 13.6 & 21.8 \\
\hline Kazakhstan & 6252 & 73.5 & 63.0 & Syrian Arab Republic & 1623 & 15.6 & 21.5 \\
\hline Jordan & 1237 & 39.4 & 61.0 & Afghanistan & 1695 & 10.5 & 20.6 \\
\hline Syrian Arab Republic & 4140 & 39.7 & 52.5 & Iraq & 1983 & 11.8 & 19.3 \\
\hline Korea, Republic of & 17140 & 70.3 & 52.1 & Malaysia & 2572 & 17.8 & 18.9 \\
\hline Japan & 55710 & 85.9 & 51.5 & State of Palestine & 223 & 10.6 & 18.3 \\
\hline Pakistan & 34038 & 38.4 & 50.3 & Kazakhstan & 1865 & 21.9 & 18.0 \\
\hline Brunei & 83 & 40.6 & 48.6 & Philippines & 6621 & 13.8 & 17.8 \\
\hline Philippines & 18327 & 38.1 & 47.0 & Kuwait & 103 & 8.8 & 17.3 \\
\hline Kuwait & 314 & 26.9 & 46.7 & Israel & 990 & 25.4 & 17.3 \\
\hline Qatar & 148 & 31.6 & 46.1 & Indonesia & 19750 & 16.1 & 16.6 \\
\hline State of Palestine & 578 & 27.5 & 44.0 & Timor-Leste & 52 & 8.9 & 16.4 \\
\hline Georgia & 1541 & 67.7 & 44.0 & Singapore & 628 & 24.1 & 15.5 \\
\hline Iraq & 4542 & 27.1 & 42.6 & Yemen & 997 & 7.9 & 14.9 \\
\hline Bahrain & 177 & 34.7 & 42.5 & Korea, Democratic Republic of & 2340 & 18.7 & 14.3 \\
\hline Indonesia & 48998 & 39.9 & 40.3 & Turkey & 5199 & 13.9 & 13.4 \\
\hline United Arab Emirates & 568 & 22.8 & 39.2 & Georgia & 530 & 23.3 & 13.2 \\
\hline Turkey & 15230 & 40.8 & 39.1 & India & 70218 & 11.5 & 12.7 \\
\hline Malaysia & 5410 & 37.4 & 38.7 & Maldives & 14 & 8.7 & 11.5 \\
\hline Korea, Democratic Republic of & 5707 & 45.7 & 36.8 & Brunei & 18 & 8.8 & 11.3 \\
\hline Afghanistan & 3108 & 19.3 & 35.1 & Myanmar & 2792 & 11.3 & 11.3 \\
\hline Timor-Leste & 108 & 18.6 & 32.6 & Kyrgyzstan & 265 & 9.6 & 11.2 \\
\hline Maldives & 41 & 25.5 & 31.6 & Qatar & 31 & 6.6 & 11.2 \\
\hline Sri Lanka & 3955 & 36.8 & 30.9 & Bahrain & 42 & 8.2 & 11.1 \\
\hline Saudi Arabia & 2791 & 21.7 & 29.5 & Bangladesh & 7142 & 9.5 & 11.0 \\
\hline Thailand & 13653 & 38.4 & 29.3 & Thailand & 5092 & 14.3 & 11.0 \\
\hline Iran, Islamic Republic of & 9795 & 26.3 & 28.1 & Uzbekistan & 1269 & 9.0 & 10.6 \\
\hline Yemen & 1963 & 15.5 & 27.4 & United Arab Emirates & 124 & 5.0 & 10.5 \\
\hline Kyrgyzstan & 662 & 24.0 & 27.3 & Sri Lanka & 1361 & 12.6 & 10.3 \\
\hline Uzbekistan & 3370 & 23.9 & 27.1 & Viet Nam & 4671 & 10.3 & 9.9 \\
\hline Turkmenistan & 656 & 25.0 & 26.8 & Iran, Islamic Republic of & 3304 & 8.9 & 9.9 \\
\hline Oman & 195 & 16.4 & 26.0 & Japan & 13801 & 21.3 & 9.8 \\
\hline India & 144937 & 23.8 & 25.8 & Turkmenistan & 224 & 8.5 & 9.6 \\
\hline Azerbaijan & 1413 & 29.7 & 25.4 & Oman & 65 & 5.5 & 9.5 \\
\hline Viet Nam & 11067 & 24.4 & 23.0 & Cambodia & 585 & 7.9 & 9.3 \\
\hline China & 187213 & 28.6 & 22.1 & Lao PDR & 222 & 7.0 & 9.3 \\
\hline Myanmar & 5648 & 22.9 & 22.1 & Saudi Arabia & 795 & 6.2 & 9.1 \\
\hline Bangladesh & 14836 & 19.7 & 21.7 & Tajikistan & 210 & 5.8 & 8.7 \\
\hline Tajikistan & 520 & 14.4 & 20.4 & Azerbaijan & 471 & 9.9 & 8.6 \\
\hline Cambodia & 1255 & 17.0 & 19.3 & Nepal & 865 & 5.5 & 7.2 \\
\hline Lao PDR & 472 & 14.8 & 19.0 & Korea, Republic of & 2274 & 9.3 & 6.1 \\
\hline Nepal & 1716 & 11.0 & 13.7 & China & 47984 & 7.3 & 5.4 \\
\hline Mongolia & 125 & 8.7 & 9.4 & Mongolia & 50 & 3.5 & 4.2 \\
\hline Bhutan & 13 & 3.7 & 4.6 & Bhutan & 5 & 1.4 & 1.8 \\
\hline
\end{tabular}


Mahshid Ghoncheh et al

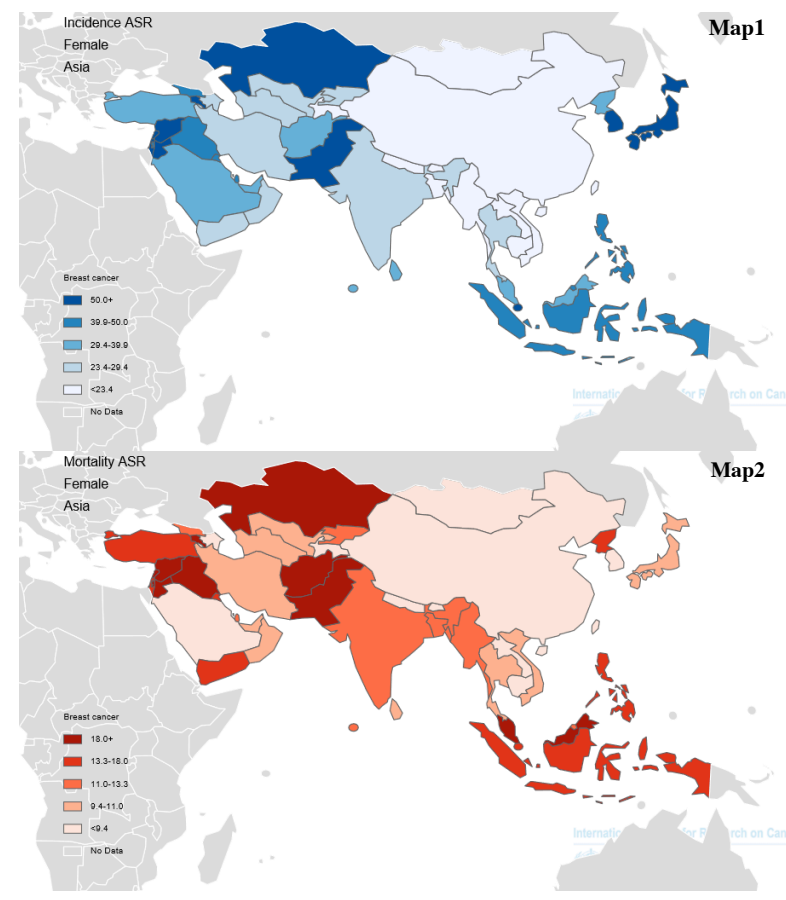

Map 1: Distribution of the standardized incidence rate of breast cancer in Asia in 2012; Map 2: Distribution of standardized breast cancer mortality rates in Asia in 2012

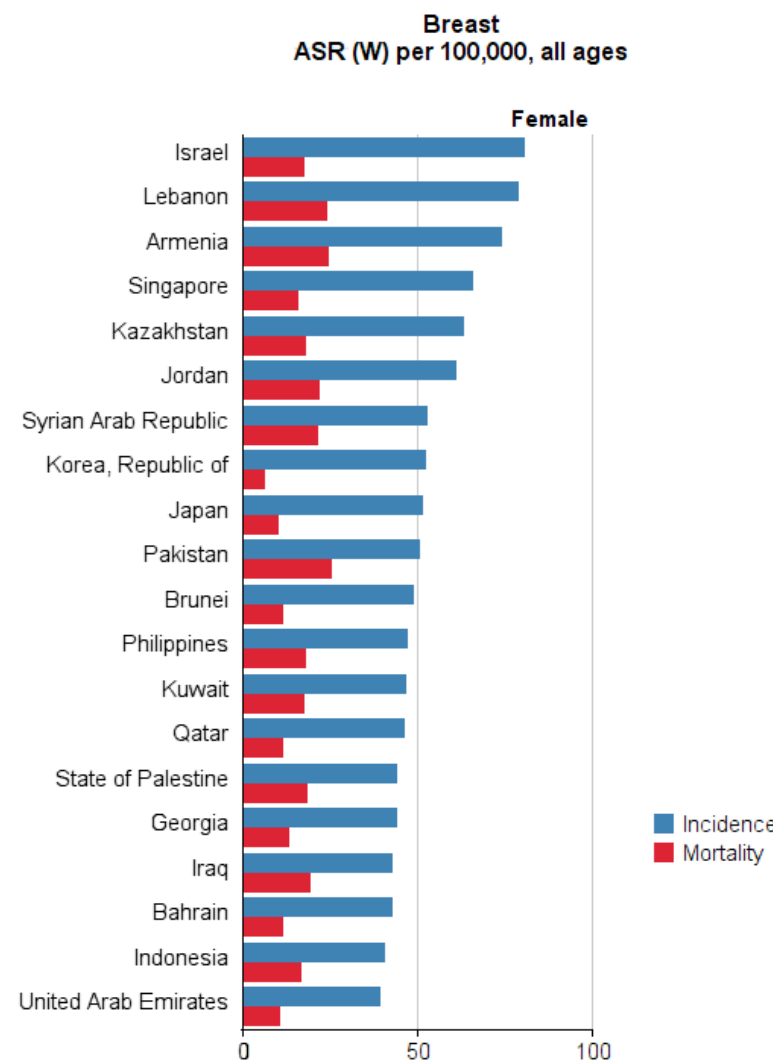

Figure 1. Incidence and Mortality of breast Cancer in Asia by Country

(19,750 cases), Pakistan (16,232 cases), and Japan (13,801 cases), respectively. A total of 167,985 cases $(73.37 \%)$ of the deaths occurred in just five countries.

In Asian countries, 5 countries with the highest standardized death rates (per 100,000) from breast

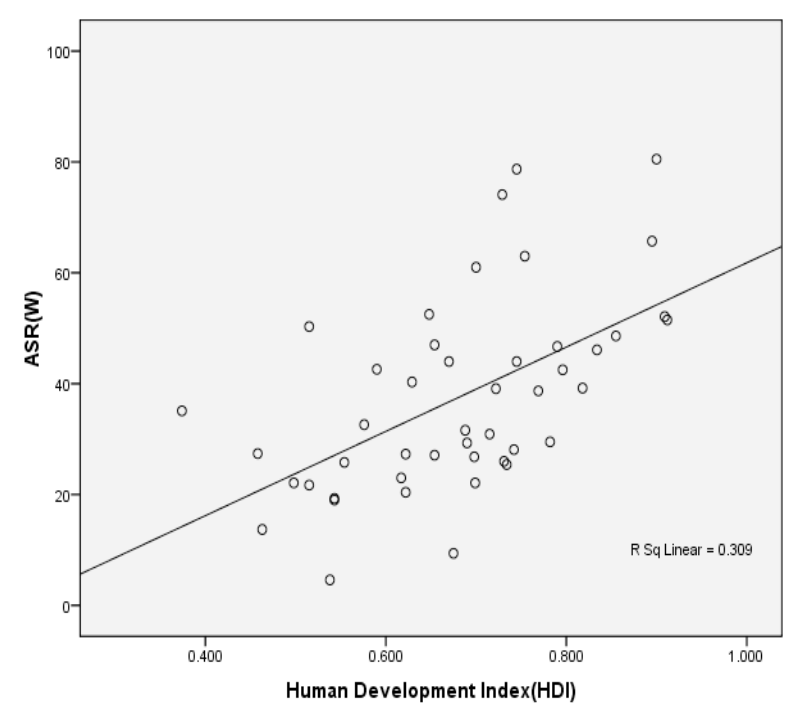

Figure 2. Correlation between HDI and Standardized Incidence of breast cancer in Asia in 2012

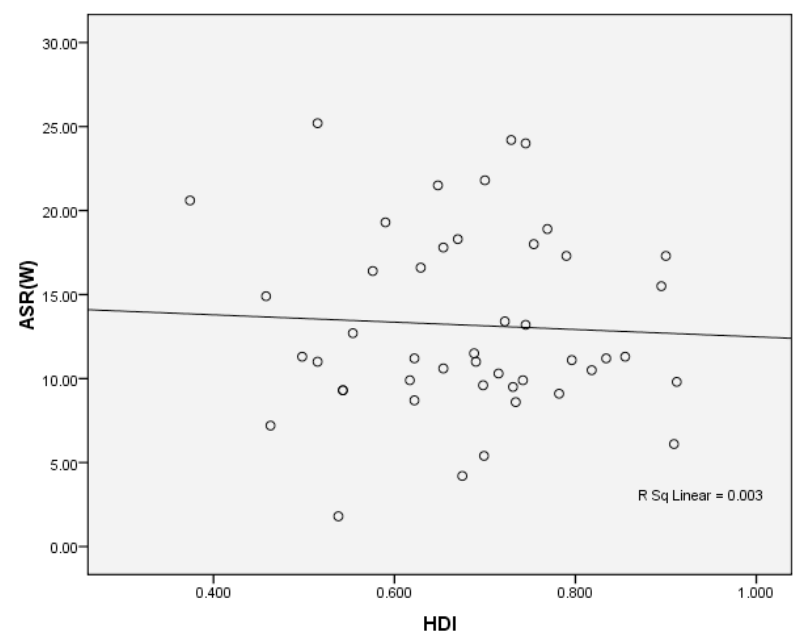

Figure 3. Correlation between HDI and Standardized breast Cancer mortality rates in Asia in 2012

cancer were Pakistan (25.2), Armenia (24.2), Lebanon (24), Jordan (21.8), and Syria (21.5), respectively. Five countries have the lowest standardized mortality from breast cancer (per 100,000) included Butane (1.8), Mongolia (4.2), China (5.4), Republic of Korea (1.6), and Nepal (2.7), respectively (Figure 1, Table1, Map 2).

Amounts related to HDI and each of its components (life expectancy at birth in 2012, the average years of schooling in 2010, and the level of income for each one of the country's population in 2012) for each of the Asian countries is shown in Table 2.

There was a positive correlation of 0.556 between the standardized incidence rate of breast cancer and HDI. This relationship was statistically significant ( $p$ $<0.001$ ). Positive correlation was also observed between the components of HDI and the standardized incidence rate. Positive correlation was $0.443(\mathrm{p}=0.002)$ between the standardized incidence rate and life expectancy at birth, $0.497(\mathrm{p}<0.001)$ between the standardized incidence rate and the average years of schooling, and $0.364(\mathrm{p}=0.013)$ between the standardized incidence rate and the level of income for each one of the country's population (Figure 2).

On the other hand, there was a negative correlation of 
Table 2. HDI and Its Component in Asian Country

\begin{tabular}{|c|c|c|c|c|}
\hline Country & $\begin{array}{l}\text { Human Development } \\
\text { Index(HDI) }\end{array}$ & $\begin{array}{l}\text { Life expectancy } \\
\text { at birth }\end{array}$ & $\begin{array}{l}\text { Mean Year } \\
\text { of schooling }\end{array}$ & $\begin{array}{c}\text { Gross national } \\
\text { income (GNI) } \\
\text { per capita }\end{array}$ \\
\hline Pakistan & 0.515 & 65.7 & 4.9 & 2566 \\
\hline Armenia & 0.729 & 74.4 & 10.8 & 5540 \\
\hline Lebanon & 0.745 & 72.8 & 7.9 & 12364 \\
\hline Jordan & 0.7 & 73.5 & 8.6 & 5272 \\
\hline Syrian Arab Republic & 0.648 & 76 & 5.7 & 4674 \\
\hline Afghanistan & 0.374 & 49.1 & 3.1 & 1000 \\
\hline Iraq & 0.59 & 69.6 & 5.6 & 3557 \\
\hline Malaysia & 0.769 & 74.5 & 9.5 & 13676 \\
\hline State of Palestine & 0.67 & 73 & 8 & 3359 \\
\hline Kazakhstan & 0.754 & 67.4 & 10.4 & 10451 \\
\hline Philippines & 0.654 & 69 & 8.9 & 3752 \\
\hline Kuwait & 0.79 & 74.7 & 6.1 & 52793 \\
\hline Israel & 0.900 & 81.9 & 11.9 & 26224 \\
\hline Indonesia & 0.629 & 69.8 & 5.8 & 4154 \\
\hline Timor-Leste & 0.576 & 62.9 & 4.4 & 5446 \\
\hline Singapore & 0.895 & 81.2 & 10.1 & 52613 \\
\hline Yemen & 0.458 & 65.9 & 5.3 & 928 \\
\hline Korea, Democratic Republic of & - & - & - & - \\
\hline Turkey & 0.722 & 74.2 & 6.5 & 13710 \\
\hline Georgia & 0.745 & 73.9 & 12.1 & 5005 \\
\hline India & 0.554 & 65.8 & 4.4 & 3285 \\
\hline Maldives & 0.688 & 77.1 & 5.8 & 7478 \\
\hline Brunei & 0.855 & 78.1 & 8.6 & 45690 \\
\hline Myanmar & 0.498 & 65.7 & 3.9 & 1817 \\
\hline Kyrgyzstan & 0.622 & 68 & 9.3 & 2009 \\
\hline Qatar & 0.834 & 78.5 & 7.3 & 87478 \\
\hline Bahrain & 0.796 & 75.2 & 9.4 & 19154 \\
\hline Bangladesh & 0.515 & 69.2 & 4.8 & 1785 \\
\hline Thailand & 0.69 & 74.3 & 6.6 & 7722 \\
\hline Uzbekistan & 0.654 & 68.6 & 10 & 3201 \\
\hline United Arab Emirates & 0.818 & 76.7 & 8.9 & 42716 \\
\hline Sri Lanka & 0.715 & 75.1 & 9.3 & 5170 \\
\hline Viet Nam & 0.617 & 75.4 & 5.5 & 2970 \\
\hline Iran, Islamic Republic of & 0.742 & 73.2 & 7.8 & 10695 \\
\hline Japan & 0.912 & 83.6 & 11.6 & 32545 \\
\hline Turkmenistan & 0.698 & 65.2 & 9.9 & 7782 \\
\hline Oman & 0.731 & 73.2 & 5.5 & 24092 \\
\hline Cambodia & 0.543 & 63.6 & 5.8 & 2095 \\
\hline Lao PDR & 0.543 & 67.8 & 4.6 & 2435 \\
\hline Saudi Arabia & 0.782 & 74.1 & 7.8 & 22616 \\
\hline Tajikistan & 0.622 & 67.8 & 9.8 & 2119 \\
\hline Azerbaijan & 0.734 & 70.9 & 11.2 & 8153 \\
\hline Nepal & 0.463 & 69.1 & 3.2 & 1137 \\
\hline Korea, Republic of & 0.909 & 80.7 & 11.6 & 28231 \\
\hline China & 0.699 & 73.7 & 7.5 & 7945 \\
\hline Mongolia & 0.675 & 68.8 & 8.3 & 4245 \\
\hline Bhutan & 0.538 & 67.6 & 2.3 & 5246 \\
\hline
\end{tabular}

0.051 between the standardized mortality rate of breast cancer and HDI. This relationship was not statistically significant $(\mathrm{p}=0.736)$. Negative and no significant correlation was $0.099(\mathrm{p}=0.514)$ between the standardized mortality rate and life expectancy at birth, 0.025 ( $\mathrm{p}<0.871)$ between the standardized mortality rate and the average years of schooling, and $0.065(\mathrm{p}=0.669)$ between the standardized mortality rate and the level of income for each one of the country's population (Figure3).

\section{Discussion}

The incidence of cancer is increasing in the developing countries (Youlden et al., 2014). Nearly $60 \%$ of the world's population lives in Asia. It should be considered the causes of incidence and mortality in the continent. Lifestyle changes in Asian countries could be a predisposing factor for cancer (Kamarudin et al., 2006).

Our findings showed that the incidence of cancer in Asia was related to HDI, which evaluates the average achievements in a country in three human dimensions (the long life, access to knowledge, and the standard of adequate living. Among Asian countries, Israel, Lebanon, Armenia, Singapore, and Kazakhstan had most standardized cancer incidence. In these countries, HDI was a range from too high, high, and moderate. In 
contrast, low incidence was observed in countries such as Bhutan, Mongolia, Nepal, Cambodia, and Tajikistan with low and medium HDI. Life expectancy at birth is one of HDI dimensions. It is directly related to the incidence of cancer as well as breast cancer. The risk of chronic diseases such as cancer increases along with the development of a country, the removal of competing causes of death, and life time increased. This can be associated with increasing the exposure time in individuals (Ferlay et al., 2010a). In some Asian countries, the incidence of breast cancer in urban areas is significantly more than rural areas. This may be due to changing lifestyles (Ferlay et al., 2010b).

One of the aspects of HDI is access to knowledge. Studies have shown the positive relationship between knowledge and individuals' behavior (Chen et al., 2014). With increasing knowledge, education, and employment, women are more likely to carry breast self-examination and search for diagnostic methods significantly increases (Ceber et al., 2013). Therefore, in these countries breast cancer is diagnosed much earlier than countries with lower levels of knowledge.

The appropriate life with a gross national income is another aspect of HDI (UNDP, 2014). According to the report of World Health Organization (WHO), with increasing income and improving living standards in developing countries, the incidence of breast cancer increases. This may be due to longer life, higher exposure to risk factors, eating more fatty foods and obesity, and lower pregnancy rates(WHO, 2013). In highincome countries, taking advantage of better diagnostic methods significantly is different from other countries (Abbastabar et al., 2013). Bray et al. found that positive correlation between HDI and cancer. With the increasing development, the incidence of cancers such as breast cancer increases and cancers associated with infectious agents reduced (Bray et al., 2012). An ecologic study showed that there is a significant relationship between nutritional factors such as consumption of fish and fruit with breast cancer. Multiple linear regression analysis indicated a significant correlation between the percentage of university education and fruits and fish consumption. The study concluded that dairy consumption, nutritional factors, health indicators, university education, and certain conditions, such as diabetes mellitus, are effective on the incidence of breast cancer (WHO, 2015a).

Mortality rate of breast cancer is different in Asia (from from 25.02 in Bhutan to 08.01 in Pakistan). The Highest standardized mortality rates occurred in Pakistan, Armenia, Lebanon, Jordan, and Syria, with moderate HDI. Countries with high incidence do not experience higher mortality. There was a negative linear relationship between mortality rate and HDI. A negative correlation also observed between HDI components (life expectancy at birth, the average years of schooling, and the level of income) and standardized mortality rate. Gonzaga et al. there was a significant relationship between HDI and cancer mortality (Gonzaga et al., 2015).

In Pakistan, for example, with the highest standardized death rate from breast cancer, cancer was in the eighth rank in the country's burden of disease, while factors such as maternal and infant mortality and death from infectious, respiratory, and nutritional diseases are still the main cause of death. In the country, standardized death rate from breast cancer than other cancers is higher. In this country, the lack of public access to radiotherapy services in the health system can be significant. A small number of medical centers than the general population is also important(WHO, 2015b). According to the logistic regression after adjusting for age, marital status, and a family history, there was a significant relationship between economic, social, and educational levels and the stage of breast cancer in Iran (Roshandel et al., 2014).

This was an ecological study. The ecological fallacy will occur if results are inferred and concluded at the individual level. The results of this study are attributable only at the population level.

Cancer incidence in countries with higher development is more, while mortality in countries with less development is more. There was a positive and significant relationship between the standardized incidence rate of breast cancer and HDI aspects (life expectancy at birth, the average years of schooling, and the level of income for each one of the country's population) and the standardized incidence rate. There was a negative and no significant relationship between the standardized mortality rate of breast cancer and HDI.

\section{References}

Abbastabar H, Hamidifard P, Roustazadeh A, et al (2013). Relationships between breast cancer and common noncommunicable disease risk factors: an ecological study. Asian Pac J Cancer Prev, 14, 5123-5.

Agarwal G, Pradeep PV, Aggarwal V, et al (2007). Spectrum of breast cancer in Asian women. World J Sur, 31, 1031-40.

Bray F, Jemal A, Grey N, et al (2012). Global cancer transitions according to the Human Development Index (2008-2030): A population-based study. Lancet Oncol, 13, 790-801.

Ceber E, Mermer G, Okcin F, et al (2013). Breast cancer risk and early diagnosis applications in Turkish women aged 50 and over. Asian Pac J Cancer Prev, 14, 5877-82.

Chen GA, Tarver SL, Wen YF, et al (2014). Correlation study of knowledge and behavior regarding breast care among female undergraduate students in China. Asian Pac J Cancer Prev, 15, 10943-7.

Ferlay J, Hery C, Autier P, et al (2010a). Global burden of breast cancer. in 'breast cancer epidemiology', Eds Springer New York, 1-19

Ferlay J, Shin H-R, Bray F, et al (2010b). Estimates of worldwide burden of cancer in 2008: GLOBOCAN 2008. Int J Cancer, 127, 2893-917.

Ferlay J SI, Ervik M, Dikshit R, et al (2013). GLOBOCAN 2012 v1.0, Cancer incidence and mortality worldwide: IARC cancer base No. 11 [Internet]. Lyon, France: International Agency for Research on Cancer [Online].

Gonzaga CMR, Freitas-Junior R, Curado MP, et al (2015). Temporal trends in female breast cancer mortality in Brazil and correlations with social inequalities: Ecological timeseries study. BMC Public Health, 15.

Grayson M (2012). Breast cancer. Nature, 485, S49-S.

Jemal A, Bray F, Center MM, et al (2011). Global cancer statistics. CA Cancer J Clin, 61, 69-90.

Kamarudin R, Shah SA, Hidayah N (2006). Lifestyle factors and breast cancer: a case-control study in Kuala Lumpur, Malaysia. Asian Pac J Cancer Prev, 7, 51. 
Keyghobadi N, Rafiemanesh H, Mohammadian-Hafshejani A, et al (2015). Epidemiology and trend of cancers in the province of kerman: southeast of Iran. Asian Pac J Cancer Prev, 16, 1409-13.

Malik K (2013). Human development report 2013. The rise of the South: Human progress in a diverse world. The Rise of the South: Human Progress in a Diverse World (March 15, 2013). UNDP-HDRO Human Development Reports.

Rahimzadeh M, Baghestani AR, Gohari MR, et al (2014). Estimation of the cure rate in Iranian breast cancer patients. Asian Pac J Cancer Prev, 15, 4839-42.

Ramadas A, Qureshi AM, Dominic NA, et al (2015). Sociodemography and medical history as predictors of healthrelated quality of life of breast cancer survivors. Asian Pac J Cancer Prev, 16, 1479-85.

Ray K, Mandal S (2004). Knowledge of cancer in West Bengal-a pilot survey. Asian Pac J Cancer Prev, 5, 205-12.

Roshandel G, Boreiri M, Sadjadi A, et al (2014). A Diversity of cancer incidence and mortality in west asian populations. Ann Global Health, 80, 346-57.

Sankaranarayanan R, Ramadas K, Qiao Y-l (2014). Managing the changing burden of cancer in Asia. BMC Med, 12, 3-

Shin H-R, Carlos MC, Varghese C (2012). Cancer control in the Asia pacific region: current status and concerns. Japanese $J$ Clin Oncol, 42, 867-81.

UNDP. 2014. Human development report [Online]. UNDP [Online].

WHO. 2013. The breast cancer conundrum. Bulletin of the World Health Organizat, 91, 626-7. [Online].

WHO. 2015a. Breast cancer: prevention and control [Online].

WHO. 2015b. Cancer country profiles 2014 [Online].

Youlden DR, Cramb SM, Yip CH, et al (2014). Incidence and mortality of female breast cancer in the Asia-Pacific region. Cancer Biol Med, 11, 101-15. 